\title{
Teses e DissertaçÕes
}

\section{Teses}

MARCIA PINHEIRO LUDWIG

Descortinando a paisagem - A construção social do espaço e o sentido do lugar: uma comunidade rural da Zona da Mata de Minas Gerais nos umbrais do século XXI

Data: 01.07 .03

Orientador(a): Profa. Dra. Maria Irene Szmrecsanyi

NINA MARIA JAMRA TSUKUMO

A paisagem como construção da arquitetura

Data: 01.08 .03

Orientador(a): Prof. Dr. Júlio Roberto Katinsky

\section{LUIZA NAOMI IWAKAMI}

Espaços da reestruturação industrial - Alterações urbanas do Grande ABC paulista

Data: 04.08 .03

Orientador(a): Profa. Dra. Sueli Terezinha Ramos Schiffer

\section{ANGÉLICA APARECIDA TANUS BENATTI ALVIM}

A contribuição do Comitê do Alto Tietê a gestão da Bacia Metropolitana, 1994-2001

Data: 04.08 .03

Orientador(a): Prof. Dr. José Luiz Caruso Ronca

\section{RICARDO HERNAN MEDRANO}

São Paulo e Buenos Aires: Urbanismo e arquitetura 1870-1915

Data: 01.09 .03

Orientador(a): Prof. Dr. Nestor Goulart Reis Filho

\section{PAULA KATAKURA}

O ensino do projeto de arquitetura

Data: 05.09 .03

Orientador(a): Prof. Dr. Joaquim Manoel Guedes

Sobrinho
CRISTINA ENGEL DE ALVAREZ

Metodologia para construção em áreas de difícil acesso e de interesse ambiental: Aplicabilidade na Antártida e nas ilhas oceânicas brasileiras Data: 10.09 .03

Orientador(a): Prof. Dr. Ualfrido Del Carlo

\section{JOÃO CARLOS DE OLIVEIRA CESAR}

A cor e percepção ambiental - Relações

arquetípicas das cores e seu uso em áreas de tratamento de saúde

Data: 12.09 .03

Orientador(a): Prof. Dra. Élide Monzeglio

JOANA CARLA SOARES GONÇALVES

A sustentabilidade do edifício alto - Uma nova geração de edifícios altos e sua inserção urbana Data: 16.09 .03

Orientador(a): Prof. Dr. Ualfrido Del Carlo

\section{ELANE RIBEIRO PEIXOTO}

Arquitetura na revista Projeto (1980-1995): Identidade, memória e não-lugares

Data: 18.09 .03

Oriantador(a): Prof. Dr. Júlio Roberto Katinsky

\section{SÔNIA HILF SCHULZ}

Mundos diferenciais na cidade: A urbanidade como experiência estética

Data: 22.09.03

Orientador(a): Profa. Dra. Marlene Yurgel

\section{NESTOR RAZENTE}

Acordo de Cooperação Paraná/BIRD: Recriando as relações intergovernamentais através do financiamento do desenvolvimento urbano Data: 25.09.03

Orientador(a): Prof. Dr. Celso Monteiro Lamparelli 


\section{MARTA ENOKIBARA}

Para além do vazio as propostas elaboradas para a Várzea do Carmo na cidade de São Paulo: Séculos XIX e XX

Data: 30.09 .03

Orientador(a): Prof. Dr. Sylvio Barros Sawaya

\section{IRVING MONTANAR FRANCO}

Desempenho de um brise-soleil automático tipo prateleira de luz em função da luminosidade e temperatura

Data: 22.10 .03

Orientador(a): Profa. Dra. Anésia Barros Frota

\section{CLICE DE TOLEDO SANJAR MAZZILLI}

Arquitetura lúdica criança, projeto e linguagem estudos de espaços infantis educativos e de lazer Data: 27.10 .03

Orientador(a): Profa. Dra. Élide Monzeglio

JOSÉ MAGALHÃES JÚNIOR

Da arquitetura da cidade à arquitetura do edifício Data: 21.11 .03

Orientador(a): Prof. Dr. Edgar Gonçalves Dente

PEDRO LUIZ ORANGE LINS DA FONSECA E SILVA

As principais portas do centro de São Paulo e a circulação dos pedestres

Data: 21.11 .03

Orientador(a): Profa. Dra. Andreina Nigriello

\section{ANAT FALBEL}

Lucjan Korngold: A trajetória de um arquiteto imigrante

Data: 01.12 .03

Orientador(a): Prof. Dr. Paulo Julio Valentino Bruna

FÁBIO JOSÉ MARTINS DE LIMA

Por uma cidade moderna: Ideários de urbanismo em jogo no concurso para Monlevade e nos projetos destacados da trajetória dos técnicos concorrentes (1931-1943)

Data: 08.12 .03

Orientador(a): Profa. Dra. Maria Cristina da S. Leme
REINALDO GUEDES MACHADO

O púlpito luso-brasileiro

Data: 15.12 .02

Orientador(a): Profa. Dra. Élide Monzeglio

\section{Dissertações}

HELENA MARIA BARÃO PEREIRA DE MELLO

A representação gráfica do projeto: Avaliação e proposta de material didático para ensino de desenho técnico e arquitetônico para tecnólogos em construção civil, modalidade edifícios

Data: 02.07.03

Orientador(a): Profa. Dra. Vera Maria Pallamin

\section{SUZEL DE OLIVEIRA SCHMIDT}

Arquitetura hospitalar: Forma, programa e condicionantes de projetos

Data: 08.07.03

Orientador(a): Prof. Dr. Siegbert Zanettini

MONICA ANTONIA VIANA

Proteção ambiental e desenvolvimento uma reflexão sobre a bacia hidrográfica Billings

Data: 14.07.03

Orientador(a): Prof. Dr. Jorge Hajime Oseki

\section{PAULO EDUARDO BARROS PIGNANELLI}

Origens históricas e involução da arquitetura: Os últimos vinte anos de projetos da Companhia de Desenvolvimento Habitacional e Urbano do Estado de São Paulo - CDHU

Data: 04.08 .03

Orientador(a): Prof. Dr. Edgar Gonçalves Dente

\section{KARINE MURACHO}

O papel do transporte coletivo na expansão e estruturação urbana do município de São Paulo: 0 Corredor Santo Amaro - 9 de Julho

Data: 06.08 .03

Orientador(a): Profa. Dra. Regina Maria Prosperi Meyer 
YEDA MARIA AKEMI INOUE

O trabalho nas áreas residenciais de Diadema:

Velhas e novas formas de exploração

Data: 07.08 .03

Orientador(a): Profa. Dra. Yvonne Miriam Martha

Mautner

ALVAMAR CARDOSO DE OLIVEIRA

Cidades da Estrada de Ferro Sorocabana:

Contribuição preliminar à implantação de políticas

públicas integradas em uma microrregião

Data: 08.08 .03

Orientador(a): Profa. Dra. Maria Ruth Amaral de

Sampaio

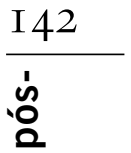

\section{LUCIANA DE ARRUDA SAMPAIO ESTEVES}

Padrões de profissionalismo para o exercício da arquitetura no Brasil: Uma reflexão sobre o tema Data: 11.08 .03

Orientador(a): Prof. Dr. Arnaldo Antonio Martino

\section{ANTONIO RODRIGUES NETTO}

As políticas urbanas no Brasil sob o prisma da estrutura socioeconômica definida pelas constituições brasileiras no período de 1930 a 1990 Data: 13.08 .03

Orientador(a): Prof. Dr. José Luiz Caruso Ronca

\section{ARTUR SIMÕES ROZESTRATEN}

Estudo sobre a história dos modelos arquitetônicos na Antiguidade: Origens e características das primeiras maquetes de arquiteto

Data: 15.08 .03

Orientador(a): Prof. Dr. Luiz Américo de Souza

Munari

\section{ALCIR CARLOS CALUX}

Amostra da arquitetura de moradias na costa sul de São Sebastião

Data: 18.08 .03

Orientador(a): Prof. Dr. João Roberto Leme Simões
ROMILDA ROSA UENO

Proposta para o desenvolvimento do design de revestimentos cerâmicos

Data: 20.08 .03

Orientador(a): Prof. Dr. Carlos Alberto Inácio

Alexandre

\section{MARIA BEATRIZ DE CAMARGO ARANHA}

Rino Levi: Arquitetura como ofício

Data: 03.09.03

Orientador(a): Profa. Dra. Fernanda Fernandes da Silva

CARLOS COSTA AMARAL JÚNIOR

O desenho da arquitetura e o caráter da cidade Dez casas de Joaquim Guedes

Data: 03.09.03

Orientador(a): Prof. Dr. Júlio Roberto Katinsky

MAURO MIGUEL MUNHOZ

A borda d'água de Paraty: Revitalização urbana sustentável a partir de seus espaços públicos de borda d'água

Data: 15.09 .03

Orientador(a): Prof. Dr. Benedito Lima de Toledo

\section{DEISE TOMOKO ODA}

Preservação e controle do uso do solo: A atuação das associações de moradores de bairro -

Associações de bairros de Z1 sob a administração regional de Vila Mariana do município de São Paulo Data: 16.09 .03

Orientador(a): Prof. Dr. Edgar Gonçalves Dente

RENATA VIEIRA DA MOTTA

O MASP em exposição: Mostras periódicas na Sete de Abril

Data: 16.09 .03

Orientador(a): Profa. Dra. Maria Cecília França

Lourenço 
LUIS EMILIANO COSTA AVENDAÑO

Interação designer-empresa no contexto estratégico do desenvolvimento do produto: Situação da pequena e média indústria moveleira do estado de São Paulo

Data: 24.09 .03

Orientador(a): Profa. Dra. Maria Cecília Loschiavo dos Santos

ANA PAULA NASCIMENTO

MAM: Museu para a metrópole

Data: 07.10 .03

Orientador(a): Profa. Dra. Maria Cecília França Lourenço

MARIA ISABEL IMBRONITO

Três edifícios de habitação para forma espaço: Modulares, gemini e protótipo

Data: 08.10 .03

Orientador(a): Prof. Dr. Eduardo Luiz Paulo

Riesencampf de Almeida

ANTHONY ROBERT JOSEPH NICHOLL

Acessibilidade e usabilidade de terminais de transação telemática no Brasil: Um estudo ergonômico

Data: 10.10 .03

Orientador(a): Prof. Dr. José Jorge Boueri Filho

\section{LINEU PASSERI JUNIOR}

Estúdios de gravação de áudio: As necessidades acústicas como indutoras do desenho

Data: 13.10 .03

Orientador(a): Prof. Dr. João Gualberto de Azevedo Baring

FERNANDA GUIGUER GUGLIELMETTI

Cenas seletivas estudo de fotografias da cidade de São Paulo no período compreendido entre 1990-

2001 - Temas, estética e interpretações

Data: 15.10 .03

Orientador(a): Prof. Dr. Carlos Alberto Inácio

Alexandre

\section{WALTER PIRES}

Configuração territorial, urbanização e patrimônio: Colônia da Glória (1876-1904)

Data: 17.10 .03

Orientador(a): Profa. Dra. Ana Lucia Duarte Lanna

\section{STELA MARIS GERVÁSIO}

O mobiliário residencial brasileiro: Design, materiais e técnicas de produção

Data: 17.10 .03

Orientador(a): Prof. Dr. Rafael Antonio Cunha

Perrone

\section{ARTUR GRISANTI MAUSBACH}

Miniônibus para o sistema vascular de transporte coletivo de São Paulo

Data: 28.10 .03

Orientador(a): Prof. Dr. Carlos Alberto Inácio

Alexandre

\section{CRISTINA GARCIA ORTEGA BERTELLA}

Móvel moderno - Uma arquitetura, repensando a identidade de princípios projetuais: O caso Gerrit

Rietveld

Data: 03.11 .03

Orientador(a): Profa. Dra. Maria Cecília Loschiavo dos Santos

ANDRÉ AUGUSTO DE ALMEIDA ALVES

Arquitetura e sociedade em São Paulo 1956-1968:

Projetos de Brasil moderno

Data: 07.11 .03

Orientador(a): Profa. Dra. Maria Lucia Caira Gitahy 